\title{
Improving Community Capacity in Rapid Disaster Mapping: An Evaluation of Summer School
}

\author{
Dewayany Sutrisno ${ }^{1}$, Peter Tian-Yuan Shih ${ }^{2}$, Mazlan bin Hashim ${ }^{3}$, RongJun Qin ${ }^{4}$, Pramaditya Wicaksono ${ }^{5}$ \\ and Rahman Syaifoel ${ }^{6}$ \\ ${ }^{1}$ Badan Informasi Geospasial (BIG), ${ }^{2}$ Department of Civil Engineering, National Chiao Tung University, \\ Hsinchu, china taipei, ${ }^{3}$ Department of Remote Sensing, Universiti Teknologi Malaysia, Johor Baru, Malaysia, \\ ${ }^{4}$ Department of Civil Environmental, and Geodetic Engineering, Ohio State University, Athens, Ohio-USA, \\ ${ }^{5}$ Faculty of Geography, Universitas Gadjah Mada, Indonesia, ${ }^{6}$ EuroUsc, Netherland.
}

Received: 2018-11-22

\section{Keywords:}

Habitat Suitability;

Rapid mapping;

summer school;

capacity building;

disaster Accepted: 2019-05-16

\begin{abstract}
Experiences with natural disasters have intensified recent efforts to enhance cooperation mechanisms among official disaster management institutions to community participation. These experiences reveal a need to enhance rapid mapping technical assistance to be developed and shared among young scientists through a summer school. However, the question arose of how effective this summer school to be used as a tool to increase scientists' understanding and capacity. This study sought to evaluate the extent to which human resource capacity building can be effectively implemented. The methods used for this evaluation is through observations, questionnaires and a weighted scoring based on knowledge, skills and attitudes' criteria. The results indicate a significant improvement in knowledge (94.56\%), skills (82\%) and attitudes $(85.20 \%)$ among the participants. Even though there are still gaps in participants' skills, the summer school
\end{abstract}

Corespondent Email: prama.wicaksono@geo.ugm.ac.id was found to be an effective way to train the young scientists for rapid mapping.

\section{Introduction}

Southeast Asian countries are prone to a range of natural disasters. These countries' disaster risk profiles can vary from earthquakes, volcanic eruptions, tsunamis, seasonal typhoons, floods, landslides, droughts and forest fires (UNISDR 2010; Babel 2016). In Southeast Asia from 2000 to 2015, floods, droughts, typhoons and landslides alone accounted for more than $80 \%$ of the region's natural disasters. These four categories may have caused $48 \%$ of the region's deaths and been responsible for more than $90 \%$ of all people affected by disasters (EM-DAT 2016 cited in Babel 2016).

Experiences with natural disasters have intensified efforts to enhance cooperation mechanisms among official disaster management institutions to community participation. The importance of shared responsibility among national and regional government institutions to community participation in disaster management has also been analyzed by Lukasiewicz et.al (2016), which accordingly it must work collectively to reduce disaster risk. These experiences reveal a need to enhance technical assistance and disaster management resources to reduce disaster-related losses and improve responses to emergency alerts. In these situations, rapid access to information is needed to improve emergency response and risk reduction management, which can only be achieved with remote sensing technology and the strongest possible community response.

Disaster centers have been established in Southeast Asian countries, such as the Association of Southeast Asian Nations' Coordinating Centre for Humanitarian Assistance on Disaster Management. Each country also has disaster management institutions, for example, Indonesia's National Agency for Disaster Management and the Philippines' National Disaster Risk Reduction and Management Council. However, disaster management information is an important issue that needs to be more discussed because disaster risk can only be reduced if the data provided is accurate.

Thus, more rapidly available ancillary information still appears to be needed. This information involves detailed data related to disaster-linked locations that is primarily obtained from local community-based institutions. Technological advances have increased the availability of higher resolution imagery through unmanned aerial vehicles (UAVs), which have been designed to be fast, agile, robust and low cost. Some countries have already used UAVs in humanitarian response operations, such as the Philippines and Indonesia (Office for the Coordination of Humanitarian Affairs 2014). Given the need for more detailed information in disaster-prone areas to be more quickly 
available and more accurate, training is urgently needed to improve local communities' capacity to provide rapid mapping. Summer schools for young scientists are an indispensable means of educating these individuals how to obtain timely and rapidly data. This study, therefore, sought to evaluate the extent to which human resource capacities can be effectively improved through a summer school for enhancing knowledge about obtaining rapid data on disaster sites. Training material on RapMet was developed, and 25 young scientists from seven Southeast Asian countries were invited to participate in the proposed summer school. The majority of young scientists are fresh graduate and have, at least a little knowledge about remote sensing and geographical information system.

\section{The Methods}

The summer school materials focused on a technique integrating near real-time remote sensing data with spatial data acquired from UAVs because this is a science-based, practical rapid mapping technique that decision makers and end users can use (Baltsavias 2013). Active and passive remote sensing data are both good tools that support each other in providing accurate and effective spatial information. An integration of UAVs with high resolution airborne interferometric synthetic-aperture radar during the Mount Sinabung eruption is an example of how useful spatial information on disasters can be (Tampubolon \& Reinhard 2015). The present study focused on developing RapMet for use during landslide emergencies since this is a major disaster that quite often occurs in Southeast Asia, including in Indonesia. The Banjarnegara Regency was selected as a case study of a landslide disaster area because this is a Central Java district that has a long history of landslides. The basic components of RapMet to be taught in summer school are shown in Figure 1 and are explained in the following subsections.

\section{Near Real-Time Remote Sensing Analysis}

In terms of primarily natural disaster response, satellite-based emergency mapping has reached a mature operational stage over the last decade (Braun \&

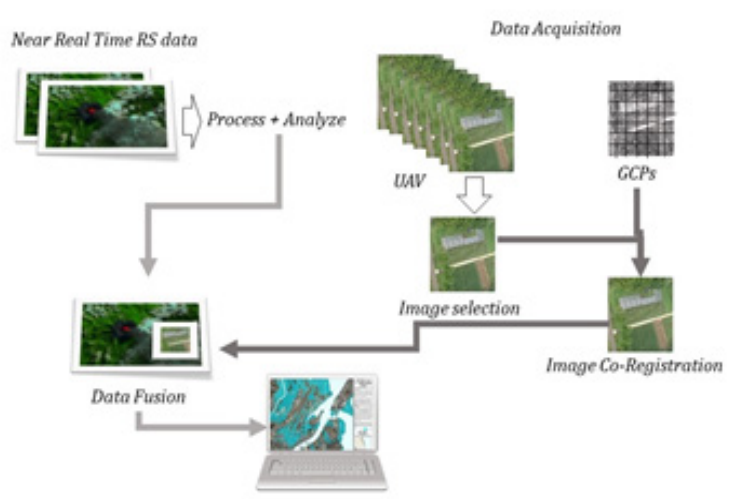

Figure 1. Flow chart of RapMet development (reproduced by permission of Sutrisno et al. 2017)
Hochschild 2017; Lang et al. 2017). However, satellite remote sensing for quick disaster response still faces challenges in real-time data collection (Zhang \& Kerle 2008). Near real-time remote sensing data has thus become the best way to provide information to disaster areas. Nonetheless, the images' resolution is always questionable because the higher the resolution, the lower the spatial information obtained - and vice versa - which means detailed, accurate information on disaster sites cannot be provided. Therefore, for training purposes, knowledge of multi sensor remote sensing to supply data to disaster-prone and affected areas still remains the best choice since participants need to learn the advantages and disadvantages of each type of sensor regarding reliable spatial information on disasters. When considering access to data, training materials can use a medium temporal resolution satellite data, such as Landsat 8 Operational Land Imager (OLI) and Sentinel-1 since these can provide reliable features to assess environmental conditions and disaster areas' infrastructure.

The method of assessment should be selected prior to disasters. The fastest approach is simply to identify the disaster-prone area after the images have been quickly geometrically corrected to meet international and/or national standards, such as the Indonesian Geospatial Reference System 2013 or SRGI 2013. An automated system for linear contrast stretching can be used to identify the nearby areas' residential and infrastructure features and other linear information, as well as to enhance the visualization of images (Chen et al. 1999; Al Amri et al. 2010, Campbell and Wynne 2011; Liu \& Mason 2013). So, the lecture material for this subsection is:

(a) Theory - remote-sensing for disaster management, the near real-time remote-sensing data needed for RapMet

(b) Practice - near real-time remote sensing and multi sensor remote sensing analysis for the case of a landslide prone area

(c) Theory and practice - GCPs and Photogrammetry

\section{Data Fusion}

None of the above remote sensing data sources can provide improved spatial information, so a role must be given to active or higher spectral resolution imageries when assessing image. The panchromatic sharpening (pan-sharpening) method thus needs to be part of the knowledge acquired by summer school participants.

Pan sharpening is used to merge high resolution panchromatic images with lower or higher resolution multispectral imagery to obtain better higher spectral images (Rajendra et al. 2012; Palsson et al. 2013). The process of obtaining a new pan sharpening image involves using a simple Brovey transform method combined with a high-pass filter. The Brovey transform is done by normalizing multispectral channels for red, green and blue displays and multiplying the results with 
high resolution (i.e. panchromatic) data to improve the images' intensity or brightness (Vrabel 1997; Mandhare et al. 2013). Brovey is the most popular method to be used in the process of pan-sharpening and has advantages in terms of visibility of clearness on size, shape, texture, pattern and object association (Hidayati e al, 2017). After that, a high pass filtering was carried out.

High-pass filtering is also the best way to map disaster areas' infrastructure or other information unavailable in previously obtained optical images. This method merges the high frequencies of panchromatic imagery with multispectral image data to obtain higher multispectral resolution images. Thus, the lecture material for this subsection is;

(a) Theory - data fusion and pan sharpening

(b) Practice - data fusion

\section{UAVs Data Acquisition and Processing}

During disasters, several forms of assistance are immediately required in the affected areas (Silva et al. 2017). Newly available low-cost UAVs have powerful capabilities in terms of capturing disaster area images (Gomez \& Kennedy 2017). UAVs equipped with digital compact cameras can be used to map landslides quickly and at a high ground resolution (Niethammer et al. 2012). Summer school participants thus need to learn how to obtain these images of affected areas and how to process and analyse the orthophoto imagery derived from UAVs' images. The process of obtaining spatial information by using UAV data is shown in Figure 2 Thus, the lecture material for this subsection is;

(a) Theory and practice- GCPs and photogrammetry for UAVs' based survey

(c) Theory - techniques of data acquisition using UAVs

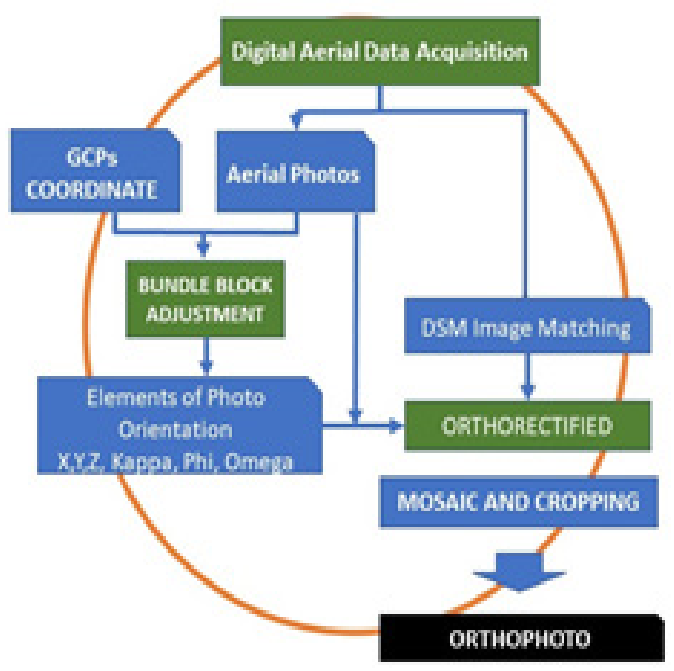

Figure 2. Process of Obtaining Spatial Information from UAVs (Gularso 2017) (d) Theory - UAVs and data processing

(e) UAVs practice - image selection, creating orthophoto images

(g) UAVs practice - UAVs simulator and mini-UAVs flying practice

(h) Practice - UAVs data acquisition field practice

\section{RapMet System and WebGIS}

All the collected and integrated information can be made easily accessible and visible to decision makers and end users in near real-time - worldwide - using WebGIS technologies. WebGIS is a combination of Web and GIS technologies that facilitate the integration, query, analysis and release of spatial data on the Internet (Zhizhan et al 2012). This technical knowledge needs to be learnt by summer school participants to allow them to communicate orthophoto UAV images - while in the field - to central systems in disaster management organisations or any community or participation command centres. Thus, the lecture material for this subsection is;

Theory - integrating near real-time remote sensing and UAV-derived data

Theory - introduction to RapMet

Theory and practice - WebGIS

Practice - RapMet presentation

Data for practicing were Landsat 8 OLI, Sentinel-1 and UAVs images for laboratory practice; hardware were computers, global positioning systems, field survey equipment and mini-UAVs and Software for remote sensing, GIS, GCPs', WebGIS, programming and UAV simulator.

LANDSAT 8 satellite has Operational Land Imager (OLI) that will collect images using nine spectral bands in different wavelengths of visible, near-infrared, and shortwave light to observe a 185 kilometer (115 mile) wide swath of the Earth in 15-30 meter and the Thermal Infrared Sensor (TIRS) Satellite imaging corp, 2017); Sentinel-1 is the European Radar observatory, revisit time, coverage, timeliness combined with frequency band, polarization, resolution and other image quality parameters and usually used for associated land and marine monitoring (Eoportal, 2019); meanwhile UAVs image is an image derived from an unmanned aircraft system (UAS) that the flight of UAVs may operate with various degrees of autonomy: either under remote control by a human operator or autonomously by onboard computers (International Civil Aviation Organization, 2011) and can be used to obtain a detail information about an area condition.

\section{Capacity Building Assessment}

Capacity building or training performance can be measured by how well required tasks or missions are completed, while objective training performance is measured by how well tasks are performed. The second category implies the use of quantitative, 
objective measurement (Orlansky et al. 1997), so the present study employed observations and a weighted scoring method to conduct quantitative assessments. The measurement instrument for observations and assessments was based on personnel competence criteria - knowledge, skills and attitudes, following the main guidelines developed by the Ministry of Manpower and Transmigration of the Republic of Indonesia (RI) (2017) The methods previously used to assess personal competence criteria has varied among researchers, still knowledge-based, acquired skills are the basic competencies to assess (Strijbos et al. 2015; Bohlouli et al. 2017; Nicolau and Constantinou 2014 and Decius and Schaper 2017). The present research's short-term learning process involved material from a field requiring more attention to and responsibility for the safety of people. Therefore, the attitude criteria had to be taken into account as these are defined by the RI's Ministry of Manpower and Transmigration (2017). The instruments for measurement was explain in Table 1.

Both knowledge and skill were measured before and after the summer school, while skill was based on observation during the training. Curricula vitae were used for the initial assessment. The tasks completed were also one of the criteria for post-summer school assessment observations. The weighted scoring method applied was defined as follows:

$$
\begin{aligned}
& v_{t_{i}}=\sum\left(v_{i_{1}}+v_{i_{2}}+\ldots+v_{i_{n}}\right) \ldots \ldots \ldots \\
& v_{t_{j}}=\sum\left(v_{1}+v_{2}+\ldots+v_{m}\right) \ldots \ldots \ldots \\
& v_{t_{k}}=\sum\left(v_{1}+v_{2}+\ldots+v_{o}\right) \ldots \ldots \ldots
\end{aligned}
$$

So that

$$
\begin{aligned}
& v_{i_{m}}=\frac{w_{n} \cdot s_{n} \cdot p_{n}}{p} ; \quad v_{j_{m}}=\frac{w_{m} s_{m} \cdot p_{m}}{p} \\
& v_{k_{o}}=\frac{w_{o} \cdot s_{o} \cdot p_{o}}{p}
\end{aligned}
$$

In which

$\nu_{t_{i}}, \nu_{t_{j}} \nu_{t_{k}}=$ total value of $i, j, k ; i=$ knowledge, $j=$ skill, $k=$ attitude; $1,2 \ldots n=$ parameter 1 to $n$ of $i ; 1,2 \ldots \mathrm{m}$ $=$ parameter 1 to $m$ of $j ; 1,2 \ldots o=$ parameter 1 to $o$ of $k$;

$w_{n}, w_{m}, w_{0}=$ weight of each parameter 1 to $n, m, 0$; $s_{n}, S_{m}, S_{o}=$ score of each parameter 1 to $n, m, o$; $p_{n}, p_{m}, p_{o}=$ number of participants at each parameter 1 to $n, m, o$; total number of participants.

The gap between participants' performance before and after summer school was analysed based on the following:
$G_{i(n)}=v_{t i}-v_{i ;} G_{j(m)}=v_{t m}-v_{m i} ; G_{k(o)}=v_{t o}-v_{o}$

In which

$G_{i(n)}$ to $G_{k(o)}=$ gap of $i, j, h$ at parameter 1 to $n, m, o$; $v i=$ $w_{n} s_{n}=$ ideal value of $i$ at parameter $n ; v_{j}=w_{m} s_{m}=$ ideal value of $j$ at parameter $m$; $v_{k}=w_{o} s_{o}=$ ideal value of $k$ at parameter $o$

\section{Result and Discussion}

Results were obtained for all 25 participants from nine Southeast Asian countries - Indonesia, Malaysia, Brunei Darussalam, the Philippines, Laos, Cambodia, Myanmar, Vietnam and Thailand. The analyses showed that the summer school participants' competence increased after the RapMet training in terms of both knowledge and skills (see Figure 3). Whilst, attitude seems remain static, since observation of attitude were carried out throughout the summer school.

In the category of understanding the theoretical basis of RapMet, almost all the desired improvement in knowledge was achieved (see Table 2, Table 3 and Figure 4). The total value of knowledge criteria (v_(t_i )) increased to $94.56 \%$ from the basic level of $43.68 \%$. Notably, the initial evaluation was based on curricula vitae and early training observations (see Table 2 below). Personal knowledge and skills usually increased after training or education sessions, but the degree of achievement varied by training topics. This variation was revealed by using gap analysis per parameter of training material, thereby showing the various levels of achievement. Slightly gap of knowledge were occurred in the fields of (a) understanding the global navigation system and map projection, (b) understanding the

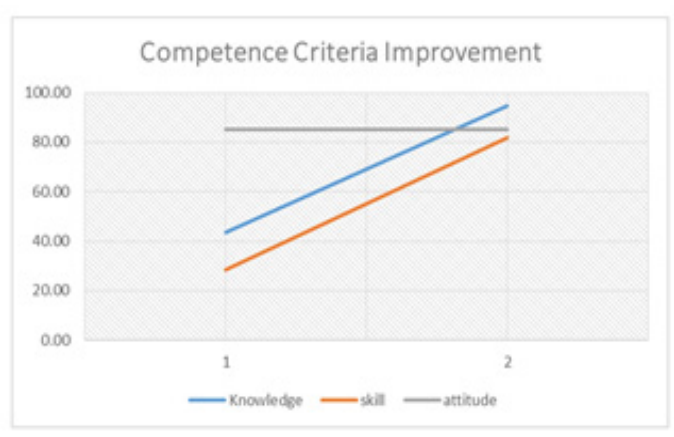

Figure 3. Competence Criteria Improvement

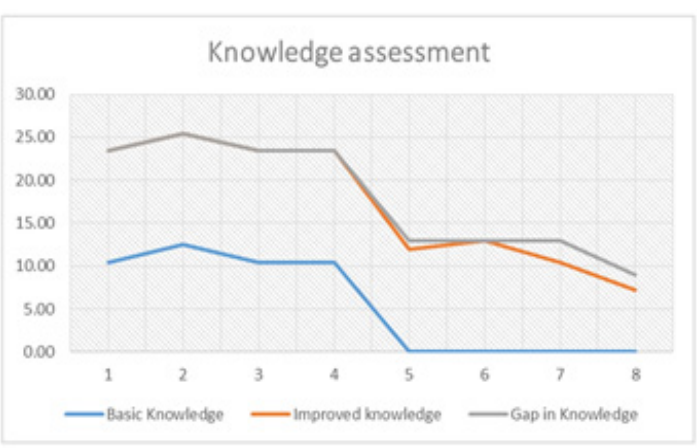

Figure 4. Knowledge Assessment After Training 
Indonesian Journal of Geography, Vol. 51 No. 2, August 2019 : 155 - 164

\begin{tabular}{|c|c|c|}
\hline \multirow[t]{2}{*}{ Lecture } & \multicolumn{2}{|l|}{ Instruments } \\
\hline & Knowledge & \multirow{5}{*}{$\begin{array}{l}\text { Skill } \\
\text { 1. Able to identify and down- } \\
\text { load the opensource software } \\
\text { for RS and GIS } \\
\text { 2. Able to operate the world } \\
\text { system to identify, searching } \\
\text { and download the RS data for } \\
\text { prior } \\
\text { assessment of the prone area } \\
\text { 3. Able to operate remote sens } \\
\text { ing and GIS software and do } \\
\text { the digital image procession } \\
\text { to identify prior knowledge of } \\
\text { the prone area by using multi } \\
\text { sensor and multi method } \\
\text { analysis. } \\
\text { 4. Able to identify prone area } \\
\text { locations and its surrounding } \\
\text { conditions' }\end{array}$} \\
\hline $\begin{array}{l}\text { Remote sensing for disaster man- } \\
\text { agement, The near real time RS for } \\
\text { RapMet }\end{array}$ & $\begin{array}{l}\text { Improve knowledge in } \\
\text { the concept of disaster } \\
\text { management }\end{array}$ & \\
\hline Near real time RS analysis & $\begin{array}{l}\text { Improve knowledge in } \\
\text { the concept of Near real } \\
\text { time RS analysis }\end{array}$ & \\
\hline $\begin{array}{l}\text { Multi sensor RS analysis for land- } \\
\text { slide }\end{array}$ & $\begin{array}{l}\text { Improve knowledge } \\
\text { in the Multi sensor RS } \\
\text { analysis for disaster }\end{array}$ & \\
\hline $\begin{array}{l}\text { Data fusion and change detection } \\
\text { Data fusion analysis }\end{array}$ & $\begin{array}{l}\text { Improve knowledge in } \\
\text { data fusion, data integra- } \\
\text { tion, pan-sharpening and } \\
\text { enhancement }\end{array}$ & \\
\hline GCPs dan Photogrammetry & $\begin{array}{l}\text { Understanding global } \\
\text { navigation system and } \\
\text { map projection }\end{array}$ & $\begin{array}{l}\text { Able to collect GCP and its } \\
\text { related flying track }\end{array}$ \\
\hline $\begin{array}{l}\text { GCPs and photogrammetry based } \\
\text { on rapid survey methods } \\
\text { GCPs and photogrammetry analysis } \\
\text { techniques of data acquisition using } \\
\text { UAVs }\end{array}$ & \multirow[t]{3}{*}{$\begin{array}{l}\text { Understanding Survey- } \\
\text { ing and data acquisition } \\
\text { using drone }\end{array}$} & \multirow[t]{3}{*}{$\begin{array}{l}\text { Able to operate drone for } \\
\text { mapping the prone area }\end{array}$} \\
\hline $\begin{array}{l}\text { UAVs simulator and mini-UAVs } \\
\text { flying practice }\end{array}$ & & \\
\hline UAVs data acquisition field practice & & \\
\hline $\begin{array}{l}\text { image selection } \\
\text { UAVs and data processing }\end{array}$ & \multirow[t]{2}{*}{$\begin{array}{l}\text { Understanding the or- } \\
\text { thophoto process }\end{array}$} & $\begin{array}{l}\text { Able to do image selection and } \\
\text { mosaicking }\end{array}$ \\
\hline creating orthophoto images & & Able to do orthophoto image \\
\hline $\begin{array}{l}\text { integrating near real-time remote } \\
\text { sensing and UAV-derived data } \\
\text { introduction to RapMet } \\
\text { introduction to RapMet }\end{array}$ & \multirow[t]{2}{*}{$\begin{array}{l}\text { Understanding the } \\
\text { concept of WebGIS and } \\
\text { RapMet Method }\end{array}$} & \multirow[t]{2}{*}{$\begin{array}{l}\text { Able to integrate the UAVs } \\
\text { derive data to the RapMet } \\
\text { System } \\
\text { Able to operate WebGIS }\end{array}$} \\
\hline RapMet presentation & & \\
\hline
\end{tabular}

orthophoto processing and (c) understanding the concept of webGIS and rapid mapping method.

In the category of skill, the improvements in skills were clearly seen in the Table 4 . The total value of skills criteria ( $v_{-}\left(\mathrm{t} \_\mathrm{j}\right)$ ) increased to $82 \%$ from $28.40 \%$. However, in the skill category some parameters were not fully matched, as indicated by the value of the gap (i.e. > 0) (see Table 4 and Figure 5 below). These parameters are operating UAVs to map disaster areas inaccessible to humans, creating orthophoto images and operating WebGIS.

Although the short time available may have caused problems in improving the participants' skills in some fields, the knowledge, methods and steps that must be employed to apply RapMet were fully understood by the participants, such as pan sharpening and filtering. Filtering method based on pan sharpening of band 8 Pan of Landsat 8 OLI and Landsat 8 OLI MSS, and Sentinel-1 images are also able to capture landslide susceptibility more clearly. The participants can thus quite easily identify landslide areas where no greenness appears, so this method can help experts predict landslide prone area and decide strategies for humanitarian aid, post disasters management actions (Ghandi et al. 2015). Mwaniki et al. (2017) demonstrated that the integration of both active and passive, either MSS and pan, imageries can capture geological features and structures that emphasize regions' high landslide 
Table 2. Basic Assessment Instruments

\begin{tabular}{|c|c|c|c|c|c|}
\hline Knowledge Criteria & Weigh $\mathrm{t}$ & Score & $\begin{array}{l}\text { No Participants/ } \\
\text { competence } \\
\text { criteria }\end{array}$ & $\begin{array}{l}\text { Total value / } \\
\text { item }\end{array}$ & $\begin{array}{l}\text { Score } \\
\text { gab /items }\end{array}$ \\
\hline \multicolumn{6}{|l|}{ Knowledge } \\
\hline $\begin{array}{l}\text { Understand the concept of disaster manage- } \\
\text { ment }\end{array}$ & 13 & 1 & 24 & 12.48 & 0.9 \\
\hline $\begin{array}{l}\text { Have experiences in the implementation of } \\
\text { Remote sensing for disaster: multi sensor \& } \\
\text { near real time }\end{array}$ & 13 & 1 & 20 & 10.40 & 1.0 \\
\hline $\begin{array}{l}\text { Having basic background in digital image } \\
\text { processing for near real time RS data, such as } \\
\text { NOAA, Feng Yun }\end{array}$ & 13 & 1 & 20 & 10.40 & 1.0 \\
\hline $\begin{array}{l}\text { Having basic background in digital image } \\
\text { processing for Multi sensor RS data (fusion, } \\
\text { pan-sharpening, change detection) }\end{array}$ & 13 & 1 & 20 & 10.40 & 1.0 \\
\hline $\begin{array}{l}\text { Understanding global navigation system and } \\
\text { map projection }\end{array}$ & 13 & 0 & 0 & 0.00 & 1.0 \\
\hline $\begin{array}{l}\text { Understanding surveying and data acquisition } \\
\text { using drone }\end{array}$ & 13 & 0 & 0 & 0.00 & 1.0 \\
\hline $\begin{array}{l}\text { Understanding the method of orthophoto } \\
\text { processing }\end{array}$ & 13 & 0 & 0 & 0.00 & 1.0 \\
\hline $\begin{array}{l}\text { Understanding the concept of WebGIS and } \\
\text { Rapid mapping }\end{array}$ & 9 & 0 & 0 & 0.00 & 1.0 \\
\hline Total knowledge value & & & 43.68 & & \\
\hline
\end{tabular}

Note: Knowledge-based $=1$, No knowledge-based $=0$, total participants $=25$ persons

susceptibility. An example of the possible results can be seen in Figure 6.

The method of UAVs to collect data rapidly for detailed information of prone area has also been understood by participants. The rapid acquisition of post disaster maps could provide a more accurate understanding of the situation on the ground, including the availability of access roads to the affected areas (Claessens et al., 2005 cited in Griffin, 2014). The role of UAVs is thus to collect data on remote locations with limited or no access.

The method to obtain orthophoto images of affected areas from UAVs images (see an example photograph in Figure 7) has also been understood by participants. The method was obtaining GCPs by using global navigation satellite systems (GNSSs), selecting and mosaicking imageries and developing orthophoto images was developed by Qin (2016) and Shih (2016). Participants learnt that GNSSs can be used not only to determine GCP coordinates but also to collect flight trajectories and provide direct observations with each camera exposure, which is extremely valuable for places difficult to access. In Shih's (2016) work, the open source GNSS processing package, RTKLIB (Takasu 2009), was introduced and used in hands-on exercises at the summer school. The Qin (2016) procedures are based on research done by Qin $(2014,2016 a)$ and Qin et al. (2012).

Another important method is WebGIS, which the participants were understood the function that can be

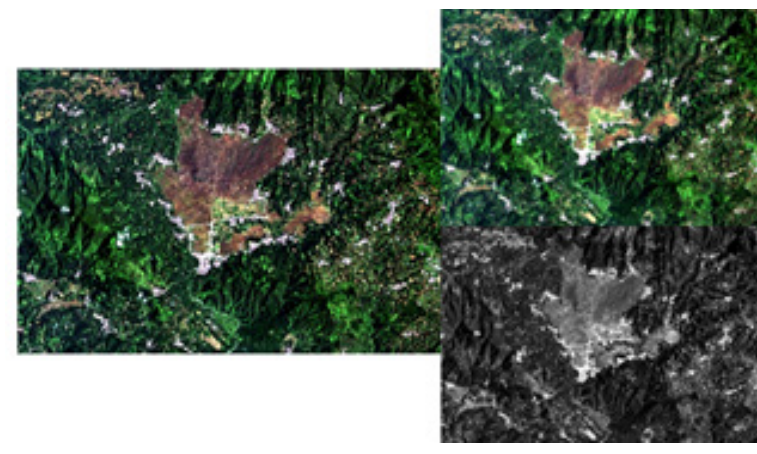

Figure 6. Pan Sharpened, Filtered Image of Affected and Nearby Areas (reproduced with permission of Sutrisno et al. 2017)

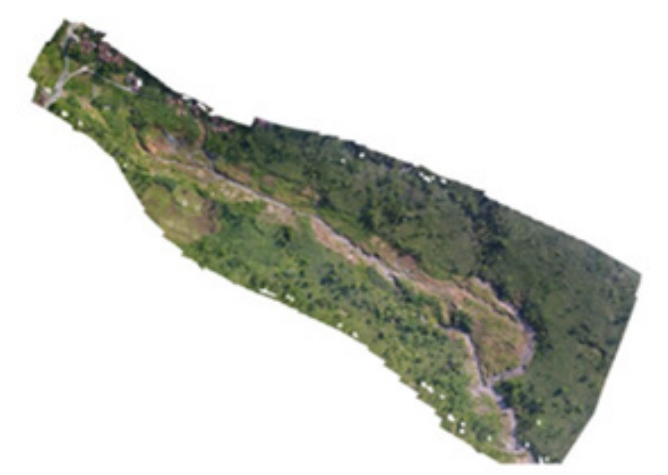

Figure 7. UAV Orthophoto Image of Affected Area (reproduced with permission of Sutrisno et al. 2017) 
Indonesian Journal of Geography, Vol. 51 No. 2, August 2019 : 155 - 164

\begin{tabular}{|c|c|c|c|c|c|}
\hline Knowledge Criteria & Weight & Score & $\begin{array}{l}\text { No Participants/ } \\
\text { competence } \\
\text { criteria }\end{array}$ & $\begin{array}{l}\text { Total value / } \\
\text { item }\end{array}$ & $\begin{array}{l}\text { Score } \\
\text { gab/ item }\end{array}$ \\
\hline \multicolumn{6}{|l|}{ Knowledge } \\
\hline $\begin{array}{l}\text { Improve knowledge in the concept of disaster } \\
\text { management }\end{array}$ & 13 & 1 & 25 & 13.00 & 0.00 \\
\hline $\begin{array}{l}\text { Improve knowledge in the concept of multi sensor } \\
\text { RS analysis }\end{array}$ & 13 & 1 & 25 & 13.00 & 0.00 \\
\hline $\begin{array}{l}\text { Improve knowledge in the concept of Near real } \\
\text { time RS analysis }\end{array}$ & 13 & 1 & 25 & 13.00 & 0.00 \\
\hline $\begin{array}{l}\text { Improve knowledge in data fusion, data integra- } \\
\text { tion, pan-sharpening and enhancement }\end{array}$ & 13 & 1 & 25 & 13.00 & 0.00 \\
\hline $\begin{array}{l}\text { Understanding global navigation system and map } \\
\text { projection }\end{array}$ & 13 & 1 & 23 & 11.96 & 1.04 \\
\hline $\begin{array}{l}\text { Understanding surveying and data acquisition } \\
\text { using drone }\end{array}$ & 13 & 1 & 25 & 13.00 & 0.00 \\
\hline Understanding the orthophoto processing & 13 & 1 & 20 & 10.40 & 2.60 \\
\hline $\begin{array}{l}\text { Understanding the concept of WebGIS and Rapid } \\
\text { mapping method }\end{array}$ & 9 & 1 & 20 & 7.20 & 1.80 \\
\hline Total knowledge value & & & & 94.56 & \\
\hline
\end{tabular}

used to upload UAV-derived maps into the RapMet system. Disaster management authorities developed preliminary images of the affected areas as mention above. Then, the more detailed map of affected areasderive UAVs can be uploaded into the previous images within the central system. An example of this process can be seen in Figure 8 .

In the future, the RapMet mobile system should be developed prior to disasters because the RapMet system can be employed by participatory mapping not only for young scientist but also for other UAV operators, stakeholders and communities. He at al. (2017) also provide a good example of a mobile post-disaster management system. The present proposed system was used to collect, share and disseminate images of disaster area and was successfully developed with a combination of native and Web applications by using various opensource software (He et al. 2017). WebGIS facilitates keeping landslide-related information consistent and up to date for any emergency response or humanitarian aid purposes (Chen et al. 2016).

\section{Conclusion}

Rapid mapping has massive potential for - and are the key to - provide rapid information to any community or disaster authorities. Brennan et al. (2016) support the idea of rapid mapping to community that portraying a spatial representation of a disasterprone area may improve the awareness of community perception on the environmental-risk. The findings ndicate that the summer school was successful and that it can play an important role in promoting faster and more effective and efficient capacity building in the field of rapid mapping. The evaluation of summer school was conducted to assess how important summer schools are for capacity building by using competence criteria approach, there is by measuring knowledge, skills and attitudes through observations, questionnaires and a weighted scoring method.

However, even though the participants' basic knowledge improved during the summer school, many skills are time and experience dependent, so they appear to need more time for practice sessions. This explains why the participants' skills acquisition was not as marked as their gains in knowledge. Using UAVs as the data acquisition tool represents more responsibility as operators must deal with safety, concentration and precision concerns. Thus, attitude was also an important aspect to be assessed in this summer school participants evaluations.

These findings show that the lecture material was effective for training participants in RapMet methods. Participants also successfully acquired the techniques and methods of acquiring data for RapMet using UAVs, UAV spatial data acquisition processing and image selection to create orthophoto images, as well as integrating near real-time remote sensing and UAVderived data. The proposed summer school program also helped participants understand and effectively use data fusion, change data analysis and WebGIS when applying RapMet.

Besides that, based on the knowledge that has been obtained, it is expected that participants can transfer their knowledge to civil society to address disaster problems in their respective countries. In addition, 


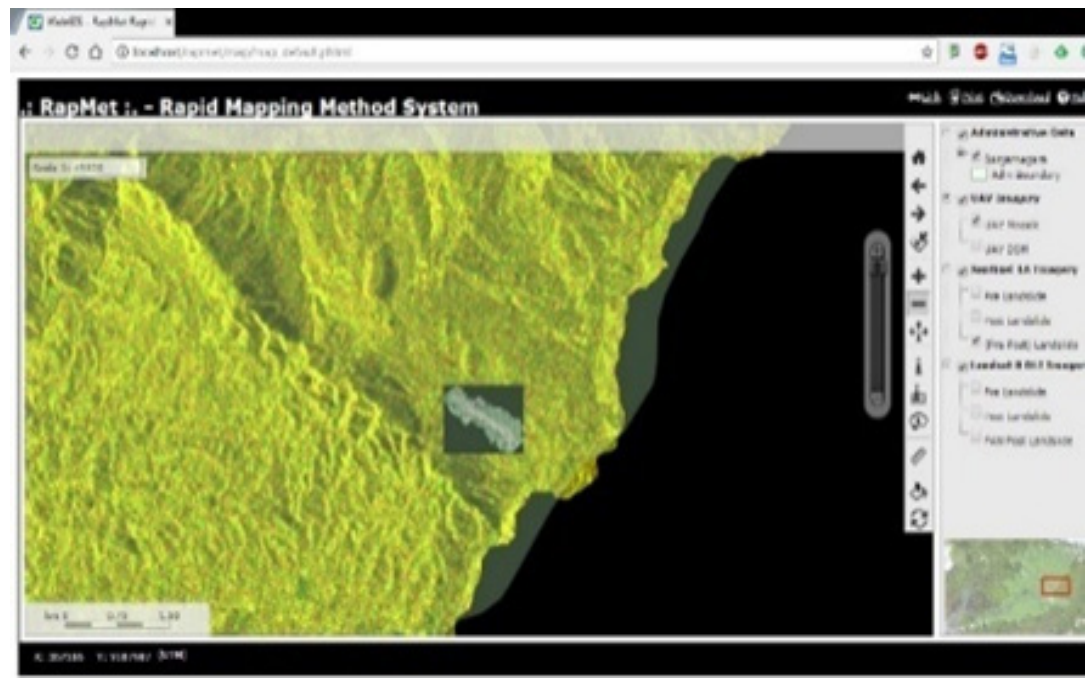

a.Uploading UAV data from the field

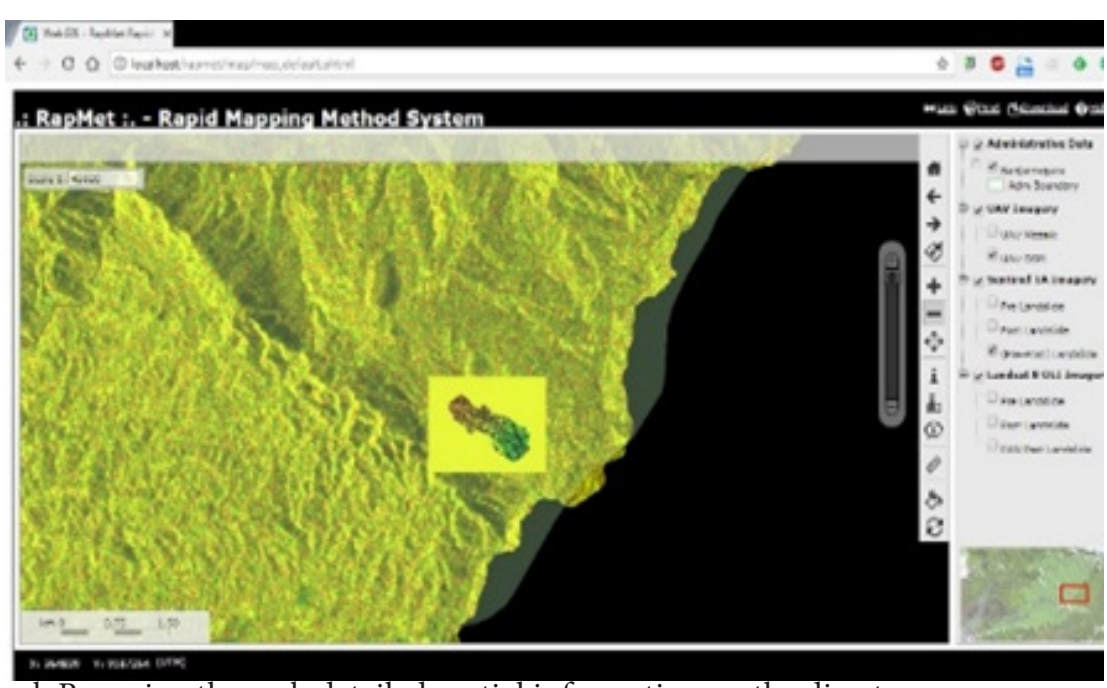

b.Browsing through detailed spatial information on the disaster area

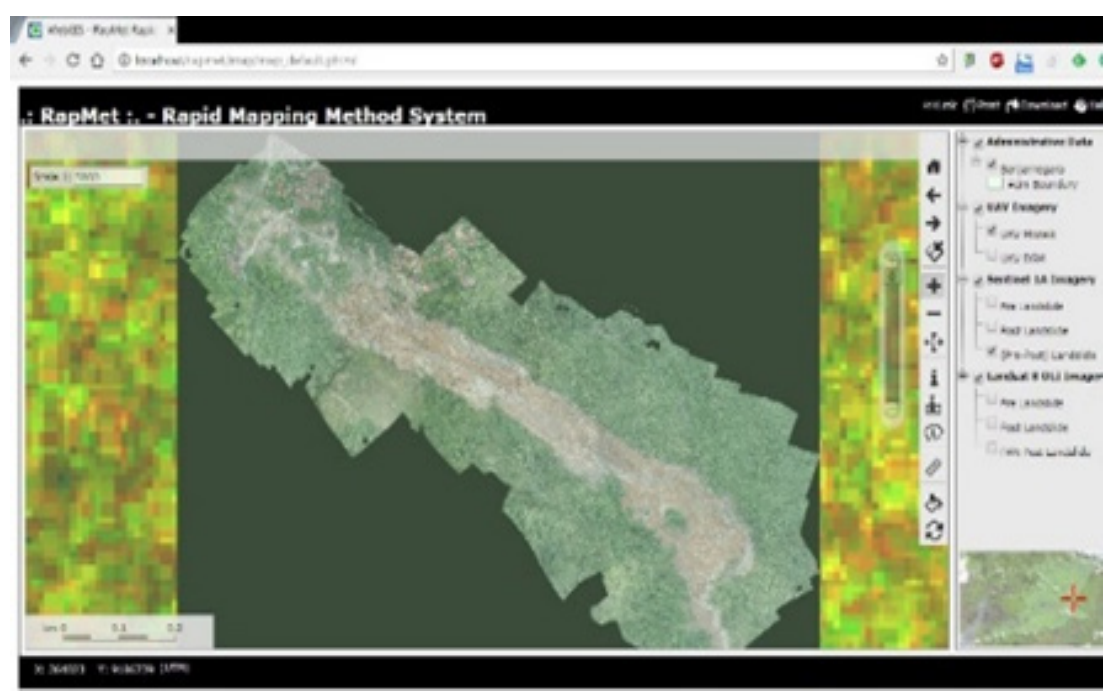

c.Browsing through detailed spatial information on the disaster-prone area

Figure 8. Example of WebGIS Application (reproduced with permission of Sutrisno et al. 2017) 
similar activities with the support of relevant regional or international institutions need to be resumed by involving wider participants in the Asia Pacific region.

\section{Acknowledgement}

We would like to express our gratitude to the Asia-Pacific Network for Global Change Research for giving us the opportunity to carry out this research; the academic community of the Universitas Gajah Mada, which assisted us in the implementation of the proposed summer school; National Chiao Tung University, which facilitated the dissemination of the training materials in the ASEAN-Taiwan forum, and our project collaborators from Universiti Teknologi Malaysia, Ohio State University and UAVs private experts whose assistance helped us carry out this research successfully. All authors contributed equally to this work.

\section{References}

Al Amri, S. S., N.V. Kalyankar \& S.D.Khamitkar. (2010). Linier and non-linier contrast enhancement image. International Journal of Computer Sciences and Network Security, 10 (2), 139-143

Babel, M.S. (2016). Disasters in ASEAN countries: Current status and research needs. 1st Symposium on JASTIP Disaster Prevention International Cooperation Research (JASTIP-WP4 Symposium). Kyoto University 24-26th 2016. Japan

Baltsavias, E, K.Cho, F.Remondino, U.Soergel \& H.Wakabayashi. (2013). Rapid mapping and information dissemination for disasters using remote sensing and geoinformation. International archives of the Photogrammetry, Remote Sensing and Spatial Information sciences, Vol XL-7/W2,2013 ISPRS2013SSG, Antalya turkey

Bohlouli, M., N. Mittas, G. Kakarontzas, T. Theodosiou, L. Angelis \& M. Fathi. (2017). Competence assessment as an expert system for human resource management: A mathematical approach. Expert System Applications, 70, 83-102, DOI: doi.org/10.1016/j.eswa.2016.10.046

Braun, A., \& V. Hochschild. (2017). Potential and limitation of radar remote sensing for humanitarian operations. GI Forum 2017,1, 1228-243, DOI:doi.org/ 10.1553/ giscience2017_01_s228

Brennan, M., E.O’Neill, F.Brereton, I.Dreoni \& H.Shahumyan. (2016). Exploring the spasial dimension of community level food risk perception: A cognitive mapping approach. Environmental Hazards, Vol 15(4), 279-310, DOI:doi.org/10.1080/17477891.2016.1202807

Campbell, J.B \& R.H.Wynne. (2011). Introduction to Remote Sensing. 5th edition. Guilford Press. USA

Chen, B., S. Latifi \& J. Kanai. (1999). Edge Enhancement of remote sensing image data in the DCT domain. Image and Vision Computing, 17(12), 913-921

Chen, W., B.He, L. Zhang \& D. Nover. (2016). Developing an integrated $2 \mathrm{D}$ and $3 \mathrm{D}$ WebGIS-based platform for effective landslide hazard management. International Journal of Disaster Risk Reduction, 20, 26-38

Civil Aviation Organization. (2011). Unmanned Aircraft Systems (UAS). ICAO, Canada

Decius J. \& N. Schaper. (2017). The Competence Management
Tool (CMT) - A new instrument to manage competence in small and medium -sized manufacturing. 7th Conference on Learning Factories (CLF 2017). Procedia Manufacturing 9(2017),376-383, DOI:doi.org/10/1016/j. promfg.2017.04.041.

De La Torre, G., M. A. Ramallo \& E.Cervantes. (2016). Workload perception in drone flight training simulators. Computer in Human Behavior. 64, 449-454, DOI: doi. org/j.chb.2016.07.040

Eoportal, 2019. Copernicus:Sentinel-1. https://directory. eoportal.org

He, Yuanrong, D. Zhang \&Y. Fang. (2017). Development of mobile post-disaster management system using free and open source technology. International Journal of Disaster Risk Reduction, 25: 101-110, DOI: doi.org/10.1016/j. ijdr.2017.08.007

Ghandi, G. M., S. Parthiban, N. Thummalu \& A. Christy. (2015). NDVI: Vegetation Change Detection using remote sensing and GIS- a case study of Vellore District. Procedia Computer Science, 57;1199-1210, DOI:doi. org/10.1016/j.procs.2015.07.415

Gomez, C., \& B. Kennedy. (2017). Capturing volcanic plumes in $3 \mathrm{D}$ with UAV-based photogrammetry at Yasur volcano - Vanuatu. Journal of Volcanology and Geothermal Research. DOI: doi.org/10.1016/j.jvolgeores.2017.12.007. Available from: https://researchgate.net/ publication/321600784_ Capturing_Volcanic_Plumes_ in_ D _with_UAV-based Photogrammetry_at_Yasur_ Volcano - Vanuatu [Accessed \& December 2017

Griffin, G.F. (2014). The used of unmanned aerial vehicles for disaster management. University of Melbourne, Center for Disaster Management and Public Safety. Geomatica, 68(4), 265-281. DOI: doi.org/10.5623/cig2014-402

Hidayati, I.N., E.Susanti, W. Utami. (2017). Analisis PanSharpening untukmeningkatkan kualitas spasial citra penginderaan jau $\mathrm{h}$ dalam klasifikasi tata guna tanah. Bhumi 3(1). DOI: 10.31292/jb.v3i1.95

Lang, S., E. Schoepfer, P. Zeil \& B. Riedler. (2017). Earth observation for humanitarian assistance. GI Forum 2017, 1, 157-165, DOI:doi.org/10.1553/Giscience2017_01_ s157

Liu, J. G. \& P. J.Mason. (2013). Essential image processing and GIS for remote sensing. Wiley-Blackwell. A John Wiley \&sons, Ltd., Publication.

Lukasiewicz, A., S. Dovers \& M.Eburn. (2017). Shared responsibility: The who, what and how. Environmental Hazards, 16(4), 291-313, DOI:doi. org/10.1080/17477891.2017.

Mandhare, R.A, P. Upadhyay \& S. Gupta. (2013). Pixel level image fusion using Brovey transform and Wavelet transform. International Journal of Advanced Research in Electrical, Electronics and Instrumentation Engineering, 2(6), $2690-2695$.

Ministry of Manpower and Transmigration Republic of Indonesia. (2017). Ministry of manpower and transmigration Republic of Indonesia decree no 95/2017 about stipulation of Indonesian national working competence standard for professional, scientific and technical activities category of architecture and engineering activities: technical analysis and assessment of geospatial information. Jakarta. Indonesia.

Mwaniki, M.W., D.N.Kura, M.K.Boitt \& T.G. Ngigi. (2017). Image enhancement of Landsat 8 (OLI) and SAR data for preliminary landslide identification and mapping applied to the central region of Kenya. 
Geomorphology,282,1620175, DOI:doi.org/10.1016/j. geomorph.2017.01.015

Nicolau, Chr.Th. \& C.P.Constantinou. (2014). Assessment of the modelling competence: A systematic review and synthesis of empirical research. Educational Research Review, 13, 52-73, DOI:doi.org/10.1016/j. edurev.2014.10.001

Niethammer, U., M.R.James, S.Rothmund, J.Traveletti \& M.Joswig. (2012). UAV-based remote sensing of The Super-Sauze landslide: Evaluation and results. Engineering Geologic, 128, 2-11, Doi: doi.org/10.1016/j. enggeo.2011.03.012

O'Connor, P., R. Flin, G. Fletcher \& P. Hemsley. (2016). Method used to evaluate the effectiveness of Flight Crew CRM training in the UK aviation Industry. Crew Resource Management: Critical Essays of Human Factors in Aviation. New York - USA: Routledge,

Orlansky, J., C. P.Hammon \& S. A. Horowitz. (1997). Indicator of Training Readiness. Institute for Defence Analysis (IDA). Virginia USA

Palsson, F., J.R. Sveinsson \& M.O. Ulfarson. (2013). A New Pansharpening algorithm based on total variation. IEEE geoscience and Remote Sensing, 11(1):318-322, DOI: doi.org/10.1109/LGRS.2013.2257669

Pang, S., M. Sun, X. Hu \& Z. Zhang. (2016). SGM-based seamline determination for urban Orthophoto Mosaicking. ISPSR Journal of Photogrammetry and Remote Sensing, 12, 1-12, DOI: doi.org/10.1016/j. isprsjprs.2015.11.007

Qin, R. (2014). An object-based hierarchical method for change detection using Unmanned Aerial Vehicle images. Remote Sensing, 6 (9), 7911-7932

Qin, R. (2016). UAV (Unmanned Aerial Vehicle) data acquisition and processing: lecture and practice presentation of summer school rapid mapping technique for disaster observation and global change data acquisition. Lecture Material. Yogjakarta - Indonesia, October 11th -17th 2016.

Qin, R. (2016a). Multi-view stereo processor. http://u.osu. edu/qin.324/msp/ (Accessed Jan, 19, 2018)

Qin, R., A. Gruen \& X. Huang. (2012). UAV Project Building a Reality-based 3D model of the NUS (National University of Singapore) Campus. Proceeding of the 33rd Asian Conference on Remote Sensing, 26 - 30 November 2012, Pattaya, Thailand. Current Associate.

Rajendra, V., D.Varghese, S. Annadurai, V. Vaithiyanathan \& B. Thamorathan. (2012). A Case study on satellite image fussion technique. Research Journal of Information Technology, 4(2), 71-78

Satellite Imaging Corp. (2017). Landsat 8 Satellite Sensor. https://www.satimagingcorp.com

Silva, K. de O., R. A. d. M. Bandeira \& V. B. G. Campos. (2017). The use of UAV and Geographic Information Systems for facility location in a post-disaster scenario. Transportation Research Procedia, 27, 1137-1145, DOI: doi.org/10.1016/j.trpro.2017.12.031

Strijbos, J., N. Engles \& K. Struyven. (2015). Criteria and standard of generic competences at bachelor degree level: A review study. Educational Research Review, 14, 18-32, DOI:doi.org/10.1016/j.edurev.2015.01.001

Shih, P. T.Y. (2016). GNSS data and processing; Lecture 3 part 1 to 3 of Rapid Mapping Technique for disaster observation and global change data acquisition. Lecture Material. Yogjakarta - Indonesia, October 11th -17th 2016
Sutrisno, D., M. B. Hashim, R. Syaifoel, R. Qin, P.T.Y.Shih \& P. Wicaksono. (2017). rapid mapping technique for disaster observation and environmental change data acquisition. APN E-Lib, accessed March 23,2018. http://www.apngrc.org/reosurces/items/2045

Takasu, T. (2009). RTKLIB: Open source program package for RTK-GPS, FOSS4G 2009, November 2 Tokyo, Japan

Tampubolon, W \& W. Reinhard. (2015). UAV data processing for Rapid Mapping activities. Commission VI, WG VI/4. ISPRS Geospatial week, 28 September - 03 october 2015, La Grande Motte, France. DOI: doi.org/10.5194/ isprsarchieves-XL-3-W3-371-2015

United Nations Office for The Coordination of Humanitarian Affairs. (2014). Occasional Policy Paper: Unmanned Aerial Vehicles in Humanitarian Response. OCHA Policy and Studies Series, June 2014|010.

UNISDR. (2010). Synthesis Report on Ten ASEAN countries Disaster Risk Assessment: ASEAN Disaster Risk Management Initiative. UNISDR.

Vrabel, J. (1996). Multispectral imagery band sharpening study. Photogrammetry Engineering and Remote Sensing, 62, 1075-1083

Zhang, Y. \&N.Kerle. (2008). Satellite remote sensing for near-real time data collection. Geospatial Information Technology for Emergency Response, Taylor and Francis Group, 14(53), 75-102. Available from https:// researchgate.net/publication/230674340__ Satellite_ Remote_Sensing_for_Near-real_time_data_collection/ [Accessed 27 May 2014]

Zhizhan, Yu, L. Run'e, W. Yanjang \& S. Xiaoiling. (2012). The Research on landslide disaster information publishing based on WebGIS. Energy Procedia, 16, 1199-1205, DOI:doi.org/10.1016/j.egypro.2012.0 